\title{
Visualization in the Teaching and Learning of Mathematics
}

\author{
Gert Kadunz and Michal Yerushalmy
}

\section{Report}

The history of visualization within mathematics education is a long one. Since the beginning of the 1980s mathematics educators are interested in the practical challenges of teaching visualization, in visualization of mathematics as exhibits in school or aligned with educational psychology and are looking for theoretical frameworks. ${ }^{1}$ Recall the earlier text of Norma Presmeg (cf. Presmeg 1986, 1994, 1997), Theodore Eisenberg's widely recognized paper "On the understanding the reluctance to visualize" (Eisenberg, 1994) and more recent analysis of visualization in mathematics education can be found in Arcavi (2003) or David (2012). Regardless of their focus these papers nearly all offer a common picture for which a mathematician's success owes a considerable amount to visualization skills (Heintz 2001). On the other hand the history of mathematics shows visualization to have been cut back and even avoided to a certain extent. In the time of Leonhard Euler the visual was also used as a means for proving or establishing the existence of a mathematical object, whereas the mathematicians of the 19th and 20th century

Organizers Co-chairs: Gert Kadunz (Austria), Michal Yerushalmy (Israel); Team Members: Mathias Hattermann (Germany), Michel Hoffmann (USA), Kyoko Kakihana (Japan), Jaehong Shin (Korea); Liaison IPC Member: Bernard Hodgson (Canada).

1 E.g. Jerome Bruner and his view on the use of images, Jean Piaget's learning theory or George Lakoff and his view on metaphors.

G. Kadunz (ه)

University of Klagenfurt, Klagenfurt, Austria

e-mail: gert.kadunz@uni-klu.ac.kr

M. Yerushalmy

University of Haifa, Haifa, Israel

e-mail: michalyr@construct.haifa.ac.il

(C) The Author(s) 2015

S.J. Cho (ed.), The Proceedings of the 12th International Congress

on Mathematical Education, DOI 10.1007/978-3-319-12688-3_41 
reduced the use of visualization for gaining new ideas when solving problems. Heuristics was the task of visualization. We suspect that this gap between the two trends was one reason why dealing with visualization became a significant topic for researchers in mathematics education.

Beyond our specific domain, for the last two decades we have seen a growing interest in the use of images as a general cultural change. It was Thomas Mitchel's dictum that the linguistic turn is followed now by a "pictorial turn" (Mitchel 1994) or Gottfried Boehms (Boehm 1994) "iconic turn”. Their concentration on visualization in cultural sciences is based on their interest in the field of visual arts and it is still increasing (Bachmann-Medick 2009). Other technology-enabled visualization developments such as medical imaging, which have introduced sophisticated methods for reconstructing and manipulating images, changed the public and scientific conventions in regard to what formerly was invisible. As happened with modern telescopes which allow us to see nearly infinite distant objects or microscopes which bring the infinitely small to our eye structures become visible and with this kind of visibility they become a part of the scientific debate. Visualization technology causes new paradigms to be developed as structures that could only speculated about are now subject of scientific debate. We may say that their ontological status has changed and in that regard images became a major epistemological factor.

Such new developments, caused substantial endeavour within cultural science into investigating the use of images from different perspectives. Mitchell (1987), Arnheim (1969) or Hessler and Mersch (2009) are examples. The introduction to "Logik des Bildlichen" (Hessler 2009), which we can translate as "The Logic of the Pictorial", focusses on the meaning of visual thinking. In this chapter they formulate several relevant questions on visualization which should be answered by a science of images. Among these questions we read: epistemology and images, the order of demonstrating or how to make thinking visible.

When we consider these short deliberations then we can recognize two positions. We have a long tradition of visualization within mathematics education which is based and supported by practical and theoretical practices. At the same time there are several recent developments within cultural science concerning visualization. Hence there is a need to find means of transmission and terms that would support the exchange of ideas and research questions between cultural science and mathematics education. A theory-based example of such means of transmission is relevant to a topic that our group explored in regard to the relevancy of the semiotic system. Here we mention the semiotics of Charles S. Peirce and more precisely, his idea of diagrammatic thinking which became a tool for investigating mathematical activities (Dörfler 2005; Hoffmann 2005).

The presentation of the visualization group at ICME12 can now be seen as a realization of the above mentioned views on visualization that reflect the diversity of challenges of visualization within mathematics education. Among these presentations we find theoretical deliberations concentrating on visual semiotics, presentations central to mathematics education visualization and curriculum attempting to use technology to bridge the gap between mathematicians and 
mathematics education views, presentations concentrated on the use of new software and newer hardware to enhance visualization and on what might develop into new paradigm of the visualization science using brain imaging technology attempting to make the invisible visible. In the next few paragraphs we attempt to sketch the group work with illustrations from the many papers ${ }^{2}$ presented.

As the first example we refer to Christoph Schreiber presenting his view on Peirce's semiotics "Semiotic Analysis of Collective Chat-Based Problem-Solving Processes". Schreiber illustrated the development of 'Semiotic Process Cards' based upon Charles Sanders Peirce's triadic sign relation. These cards were used as instruments for analyzing mathematical chat sessions. Within a certain teaching situation called 'Math Chat', students were asked to solve mathematics' problems while being restricted to the use of visible inscriptions only. The characteristics of this experimental setting was that pupils were required to document all their attempts at solving mathematical problems as visual inscriptions in written and graphical form. To develop a suitable instrument Schreiber combined an interactionist approach together with Perice's semiotic perspective. As a result Schreiber was able to describe the

Mathias Hattermann's text "Visualization-the Key Element for Expanding Geometrical Ideas to the 3D-Case" is an example of the group discussion in regard to the visual qualities of design of learning with technological tools. In his Hattermann described the activities of students at university level when using software for 3D-geometry (Cabri 3D). To do so he started with the presentation of two geometric constructions from plane geometry. Hattermann asked how do basic ideas in the context of plane geometry can foster or hinder similar constructions of 3D-geometry? It is the intimate relation between the tool used and the visible geometric diagrams or in other words the instrumental genesis of the software and the process of geometrical construction which is in the core of Hattermann's answer to his question. In this respect an experimental approach using the drag mode in 3D can help to find answers to describe the finding of a correct solution. The instrumental genesis of the utilized tool must be accomplished so that mental schemes can be used to extend basic ideas to the $3 \mathrm{D}$-case.

The design and qualities of software was one component of the "Visual Math" curriculum design story that Michal Yerushalmy presented. The challenge was to establish technology-based setting that would motivate algebra students to argue, refute, and revise conjectures, and to study whether prominent visualization habits of mathematical reasoning can become part of the routine pedagogy of school mathematics. Beyond software Yerushalmy described why did the design of an organizational map was a major challenge in finding out how known algebra tasks may be redesigned into a sequence emphasizing quasi-empirical process of reasoning. The museum view was a leading image in the design of the VisualMath interactive eBooks in algebra, functions and calculus. Based on theoretical

\footnotetext{
2 All papers presented within TSG 16 can be found at http://www.icme12.org/sub/tsg/tsg_last_ view.asp?tsg_param $=16$.
} 
framework of interactive diagrams that is based on visual-semiotic analysis, Yerushalmy design Interactive Diagrams that provide opportunities for the interactive text to present the curriculum's ideas to be the subject of the reader's inquiry.

Roza Leikin's "From a Visual to Symbolic Object in Algebra and Geometry: ERP $^{3}$ Study with Mathematically Excelling Male Adolescents" is in a sense the literal realization of our aforementioned hint "how to make the invisible visible". Leikin and coauthors performed a comparative analysis of brain activity associated with transition from visual objects to symbolic objects in algebra and geometry. The goal of this study was to examine differences in ERPs between gifted and nongifted excelling in mathematics adolescents while solving mathematical tasks in algebra and geometry. One finding regarding the giftedness effect was that, relative to gifted participants, non-gifted participants produced greater brain activity. This finding is consistent with the neural efficiency hypothesis of intelligence, stating that brighter individuals display lower brain activation while performing cognitive tasks. Another finding indicates a significantly higher brain activity connected to geometry test compared to algebra test. Hence Leikin and assumes that geometric tasks increase the participants' working memory load by keeping the visual geometric object in working memory until the problem is solved.

In addition to the aforementioned view on the relation of the visual and mathematics these examples reflect a fruitful diversity of visualization too. In this respect visualization appears to be a vivid part of research within mathematics education.

Open Access This chapter is distributed under the terms of the Creative Commons Attribution Noncommercial License, which permits any noncommercial use, distribution, and reproduction in any medium, provided the original author(s) and source are credited.

\section{References}

Arcavi, A. (2003). "The role of visual representations in the learning of mathematics." Educational Studies in Mathematics, 52, 215-241.

Arnheim, R. (1969). Visual thinking, The Regents of the University of California.

Boehm, G. (1994). Die Wiederkehr der Bilder. Was ist ein Bild? G. Boehm. München, Wilhelm Fink, 11-38.

David, M. M., \& V. S. Tomaz (2012). "The role of visual representations for structuring classroom mathematical activity." Education Studies in Mathematics, 80(3), 413-431.

Dörfler, W. (2005). Diagrammatic Thinking. Affordance and Constraints. Activity and sign: grounding mathematics education. M. Hoffmann, J. Lenhard and F. Seeger. New York, Springer: 57-66.

Eisenberg, T. (1994). “On understanding the reluctance to visualize." Zentralblatt fuer Didaktik der Mathematik, 26(4), 109-113.

Heintz, B., \& J. Huber, Eds. (2001). Mit dem Auge denken. Wien, New York, Springer.

Hoffmann, M. H. G., J. Lenhard, et al., Eds. (2005). Activity and sign. New York, Springer.

\footnotetext{
3 An event-related potential (ERP) is the measured brain response that is the direct result of a specific sensory, cognitive, or motor event.
} 
Hessler, M., \& D. Mersch, Eds. (2009). Logik des Bildlichen: Zur Kritik der ikonischen Vernunft. Bielefeld, transcript Verlag.

Mitchell, W. J. T. (1987). Iconology: image, text, ideology. Chicago, The University of Chicago Press.

Mitchell, W. J. T. (1994). Picture theory. Chicago, The University of Chicago Press.

Presmeg, N. C. (1986). "Visualisation in high school mathematics." For the Learning of Mathematics, 6(3), 42-46.

Presmeg, N. C. (1994). "The role of visually mediated processes in classroom mathematics." Zentralblatt fuer Didaktik der Mathematik, 26(4), 114-117.

Presmeg, N. C. (1997). Generalization Using Imagery in Mathematics. Mathematical reasoning: analogies, metaphors and images. L. English, D. London, Lawrence Erlbaum Associates, Inc.: 299-312. 